\title{
Temperature Dependence of the Chemical Sputtering of Amorphous Hydrogenated Carbon Films by Hydrogen
}

\author{
M. Schlüter, C. Hopf, T. Schwarz-Selinger, W. Jacob* \\ Max-Planck-Institut für Plasmaphysik, EURATOM Association, Boltzmannstr. 2, 85748 Garching, Germany
}

\begin{abstract}
The temperature dependence of chemical erosion and chemical sputtering of amorphous hydrogenated carbon films due to exposure to hydrogen atoms $\left(\mathrm{H}^{0}\right)$ alone and combined exposure to argon ions and $\mathrm{H}^{0}$ was measured in the temperature range from 110 to $950 \mathrm{~K}$. The chemical erosion yield for $\mathrm{H}^{0}$ alone is below the detection limit for temperatures below about $340 \mathrm{~K}$. It increases strongly with increasing temperature, goes through a maximum around 650 to $700 \mathrm{~K}$ and decreases again for higher temperatures. Combined exposure to $\mathrm{Ar}^{+}$and $\mathrm{H}^{0}$ results in substantial chemical sputtering yields in the temperature range below $340 \mathrm{~K}$. In this range the yield does not depend on temperature, but it increases with energy from about 1 (eroded carbon atoms per impinging $\mathrm{Ar}^{+}$ion) to about 4 if the ion energy is increased from 50 to $800 \mathrm{eV}$. For temperatures above $340 \mathrm{~K}$ the measured erosion rates show the same temperature dependence as for the $\mathrm{H}^{0}$-only case, but they are higher than for $\mathrm{H}^{0}$-only. The difference between the $\mathrm{Ar}^{+}$and $\mathrm{H}^{0}$ and the $\mathrm{H}^{0}$-only cases increases monotonically with increasing ion energy.
\end{abstract}

PACS numbers: 79.20.Rf, 52.40.Hf, 28.52.Fa, 82.65.+r

Published in Journal of Nuclear Materials: Received 30 November 2007

Accepted for publication 5 February 2008

Available online 13 February 2008

Published 15 May 2008

Journal of Nuclear Materials 376 (2008) 33-37

doi: 10.1016/j.jnucmat.2008.02.002

\section{INTRODUCTION}

Plasma-facing components in thermonuclear fusion devices have been mainly made of carbonaceous materials in the last two decades. In the present design for ITER it is also foreseen to build parts of the divertor-the strike zone-from CFC (carbon fiber composites) material [1, 2]. With this choice, erosion and redeposition of carbon accompanied by co-deposition of hydrogen isotopes is expected to be one of the dominant tritium retention mechanisms $[1,3,4]$.

The process of tritium retention in redeposited layers can roughly be separated into three steps: i) erosion, ii) transport through the boundary plasma, and iii) surface reactions of neutral carbon carrying species in remote surface areas. This article deals with the first step, the erosion process which leads to the production of volatile hydrocarbon molecules through interaction of the plasma species with carbon surfaces. The most important plasma species in this context are energetic particles (ions and neutrals) and thermal or low energetic hydrogen atoms.

From a large number of experimental studies it is well known that bombardment with hydrogen ions or the combined interaction of thermal atomic hydrogen and energetic ions leads to significantly higher sputtering yields than predicted for pure physical sputtering (see e.g. [5] or [6] and references therein). Recently, Hopf et al. [7-10] systematically investigated the combined interaction of argon ions and thermal hydrogen atoms with plasma-deposited amorphous hydrogenated carbon $(\mathrm{a}-\mathrm{C}: \mathrm{H})$ films in the low-energy region $(20$

*Corresponding author. Tel.: +49 893299 2618; fax: +49 893299 1504, Email address: Wolfgang.Jacob@ipp.mpg.de
- $800 \mathrm{eV})$. They found a significantly enhanced erosion yield compared with the sum of the individual processes - physical sputtering due to ion bombardment and chemical erosion due to hydrogen atoms. Such a synergistic effect, i.e., that the yield of the combined interaction of ions and neutrals hydrogen atoms is higher than the sum of the yields of the individual processes, has been found earlier by Vietzke et al. for the combined bombardment of graphite with $\mathrm{Ar}^{+}(5 \mathrm{keV})+\mathrm{H}^{0}$ $[11,12]$ and by Davis et al. for $\mathrm{H}^{+}(50 \mathrm{eV}$ to $3 \mathrm{keV})+\mathrm{H}^{0}$ [13]. Erosion due to the combined interaction of reactive neutrals and energetic ions was named chemical sputtering $[5,7-$ $10]$.

A key signature of chemical sputtering is the temperature dependence of the sputtering yield [5]. Despite the large number of investigations for chemical erosion and chemical sputtering of graphite (for a review of this field see Ref. [5]) only a few investigations were so far devoted to a-C:H films. On the other hand, $\mathrm{a}-\mathrm{C}: \mathrm{H}$ films represent a model system for the chemical sputtering of graphite by hydrogen ions and the study of such films helps to better understand the involved basic processes. The bulk of the studies devoted to a-C:H films addressed the measurement of the production yield of certain hydrocarbon species by mass spectrometry [11-20]. Although such experiments deliver very valuable information on the erosion process and the produced species, they do not necessarily determine the total erosion yield. The determination of total erosion yields, e.g., by ellipsometry [7-10], provides information complementary to the mass spectrometric studies.

Vietzke et al. [15, 16] investigated the chemical erosion of a-C:H films due to exposure to thermal atomic hydrogen and the chemical sputtering due to bombardment with hydrogen ions, measuring hydrocarbon $\left(\mathrm{C}_{x} \mathrm{H}_{y}\right)$ production yields by mass spectrometry. They found that the erosion yield of ther- 
mal hydrogen atoms for a-C:H films is much higher than for graphite and comparable to the yield for energetic hydrogen ions on graphite [15-18]. The temperature dependence for the erosion of a-C:H films with atomic hydrogen is similar to that of the chemical sputtering of graphite using energetic hydrogen ions [16-18].

The chemical erosion of thin, ion-beam deposited, amorphous hydrogenated carbon films due to exposure to a flux of thermal atomic hydrogen alone was extensively studied by Küppers and coworkers [21-27]. Based on a wealth of experimental data they devised an atomistic model for the chemical interaction of atomic hydrogen with such films and developed a rate equation system which allows to describe the experimentally observed temperature dependence [27]. We reemphasise that chemical erosion is a purely chemical, thermally activated reaction which requires no kinetic energy-beyond thermal levels - to enable the reaction. The experimental and, as a consequence, also the model results of Horn et al. [27] show qualitative agreement with the experimental results of Vietzke et al. [15, 16]. But the absolute yields of Horn et al. are about a factor of 10 lower than those of Vietzke et al. The absolute chemical erosion yield at the maximum temperature $\left(T_{\max }\right)$ was also determined by Schwarz-Selinger et al. [28]. The obtained value at $T_{\max }=650 \mathrm{~K}$ is $2 \pm 0.7 \times 10^{-2}$ [28].

Based on the model by Horn et al. [27] Roth and GarcíaRosales developed an analytical formula describing the chemical sputtering of graphite by hydrogen ions [29]. This formula was later revised by Roth [30]. This analytic description was developed and optimized for bombardment of graphite with energetic hydrogen ions. It is not directly applicable to erosion of a-C:H films and in particular not to the cobombardment experiments with ions and atomic hydrogen [5, 7-10].

In this article we present measurements of the temperature dependence of chemical erosion and chemical sputtering of plasma-deposited a-C:H films measured by ellipsometry. The films were exposed to a flux of atomic hydrogen alone or a combined flux of atomic hydrogen and argon ions of different energies, respectively.

\section{EXPERIMENTAL}

The particle-beam experiments were carried out in the MAJESTIX device. The experimental setup is depicted in Fig. 1 and thoroughly described in [31]. In short: For the experiments described in this report the ion source and one radical beam source were used. A beam of mass filtered argon ions was produced by a commercial Colutron G2-D low-energy ion gun system [32]. One of the radical beam sources is used to generate a flux of thermal, atomic hydrogen. Film thickness changes were measured in real time by ellipsometry. Because of the strong correlation of all physical properties of the investigated hydrocarbon layers $[33,34]$, the carbon density of the layers can be determined from the measured optical constants. This allows converting the film thickness change into the number of eroded carbon atoms. Since the impinging ion flux density is measured, erosion yields can be calculated from the

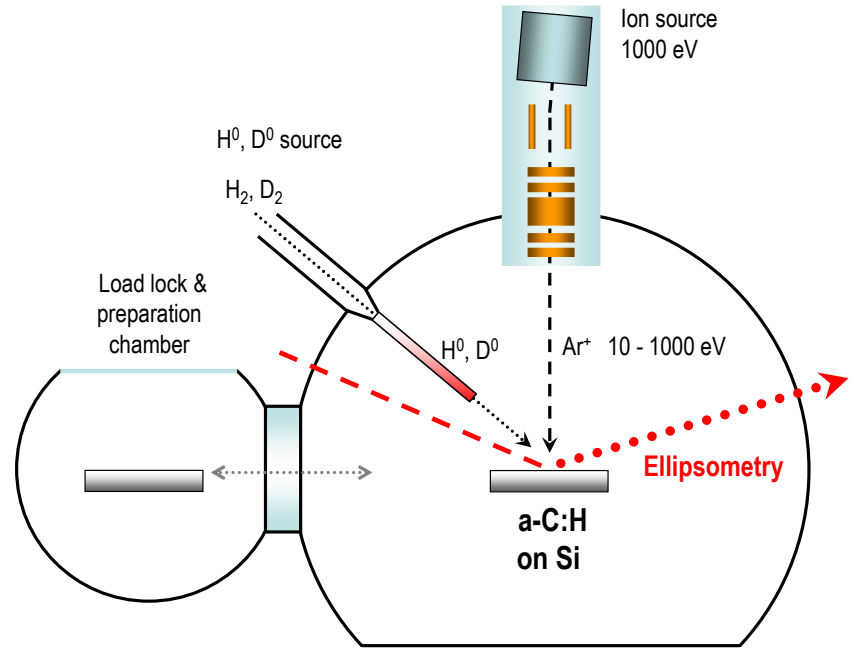

FIG. 1: Schematic representation of the MAJESTIX experiment.

erosion rates. The argon ion flux, $j_{A r}$, was $(3.5$ to 4.3$) \times 10^{12}$ $\mathrm{cm}^{-2} \mathrm{~s}^{-1}$. The atomic hydrogen flux, $j_{H^{0}}$, for all experiments presented in this article was about $1.2 \times 10^{15} \mathrm{~cm}^{-2} \mathrm{~s}^{-1}$. It was determined using the method described in Ref. [28]. For the flux calibration the erosion rate at $650 \mathrm{~K}$ is measured. From the so determined erosion rate the flux is calculated assuming the published erosion yield of $(2 \pm 0.7) \times 10^{-2}$ [28]. The yields for the exposure to atomic hydrogen are given as number of eroded carbon atoms per impinging hydrogen atom. For the cobombardment case $\left(\mathrm{Ar}+\mathrm{H}^{0}\right)$ the yields are normalized to the ion flux, i.e., they are given as number of eroded carbon atoms per impinging ion.

As samples, silicon wafers with approximately $30 \mathrm{~nm}$ thick a-C:H films were used. Amorphous hydrogenated carbon films were produced in the load lock of the MAJESTIX setup using an RF plasma with methane $\left(\mathrm{CH}_{4}\right)$ as working gas. Typical hard, diamond-like a-C:H films with a hydrogen content of $\mathrm{H} /(\mathrm{H}+\mathrm{C}) \approx 0.3$ (refractive index about 2 , density about $2 \mathrm{~g} \mathrm{~cm}^{-3}$ ) were produced at a self bias voltage of about $300 \mathrm{eV}$ $[33,34]$. The sample temperature during interaction with the particle beams is measured by a thermocouple pressed to the sample surface. The uncertainty of the temperature measurement is estimated to be about $\pm 20 \mathrm{~K}$.

The in-situ ellipsometry setup was slightly improved compared to Ref. [31]. The laser for the ellipsometer was replaced by a laser with a smaller beam diameter $(0.8 \mathrm{~mm}$ compared with $1.5 \mathrm{~mm}$ in the old setup) which allows measurements with better spatial resolution $(2.5 \mathrm{~mm}$ compared with $4.5 \mathrm{~mm}$ in the old setup). Because the beam profile of the ion beam is relatively strongly peaked, the better spatial resolution of the ellipsometer allows a more accurate determination of the erosion rates. 


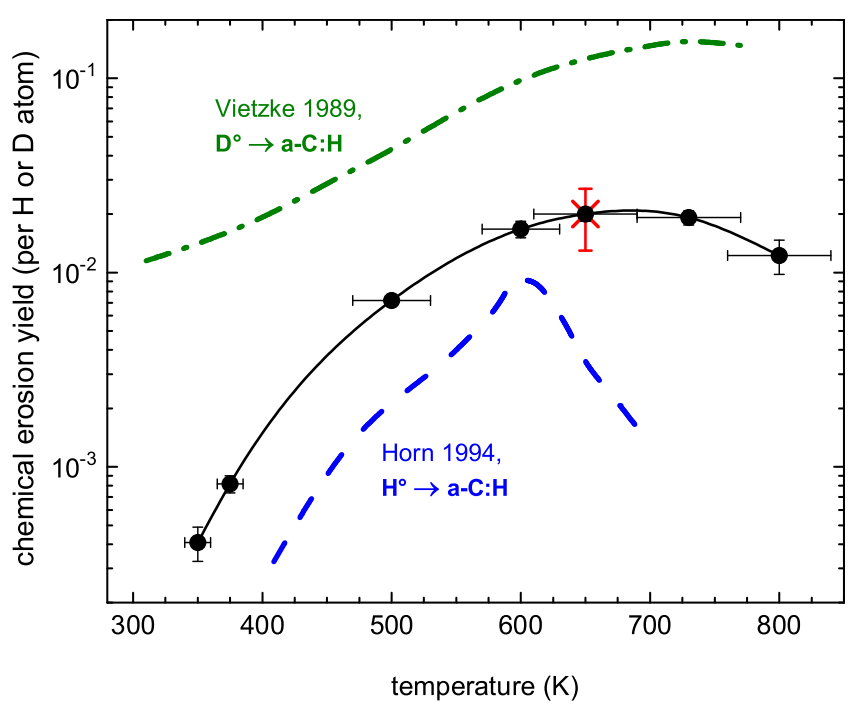

FIG. 2: Chemical erosion of a-C:H films due to exposure to a flux of thermal, atomic hydrogen $\left(j_{H^{0}}=1.2 \times 10^{15} \mathrm{~cm}^{-2} \mathrm{~s}^{-1}\right)$ as a function of temperature (solid circles, the line is only a guide to the eye). The y-error bars represent only the relative error of the data caused by the uncertainty in the determination of the eroded film thickness. For comparison, data of Vietzke et al. [17] and Horn et al. [27] are also shown. The calibration value (big cross) is taken from SchwarzSelinger et al. [28]. The associated relatively large error represents the uncertainty of the flux calibration.

\section{RESULTS AND DISCUSSION}

Fig. 2 shows the chemical erosion yield for exposure of $\mathrm{a}-\mathrm{C}: \mathrm{H}$ films to a flux of thermal hydrogen atoms as a function of sample temperature as measured by in-situ ellipsometry in MAJESTIX (solid circles). For temperatures below about $340 \mathrm{~K}$ the yield is below the detection limit of about $3 \times 10^{-4}$. Above $340 \mathrm{~K}$ it increases strongly with increasing temperature, goes through a maximum around 650 to $700 \mathrm{~K}$ and decreases again for temperatures higher than $700 \mathrm{~K}$.

The maximum yield at $650 \mathrm{~K}$ is given by the published value of $(2 \pm 0.7) \times 10^{-2}$ measured by Schwarz-Selinger et al. [28] which is als shown as big cross in Fig. 2. This value of Schwarz-Selinger et al. is used to calibrate the atomic hydrogen flux density at $T_{\max }$. With other words, our data are normalized relative to that data point.

The y-error bars in Fig. 2 are given by the uncertainty due to the determination of the total eroded film thickness. They represent the relative error of the measurement. This error is highest for the data point at $340 \mathrm{~K}$ because for this layer only a relative small thickness change was measured (see Fig. 2). For the data point at $800 \mathrm{~K}$ this contribution to the error is somewhat higher, because the optical constants of the a-C:H films change at these high temperatures. This change adds to the uncertainty in film thickness measurements. For all other data points the uncertainty due to film thickness determination are comparable to the symbol size. We emphsise that these error bars do not include the uncertainty of the calibration value.

Our data are compared to data from the literature in Fig. 2.
Vietzke et al. [17] determined the erosion of plasma-deposited $\mathrm{a}-\mathrm{C}: \mathrm{H}$ films by atomic hydrogen by measuring the time required to erode a film of given thickness (dash-dotted line in Fig. 2). It should be noted here that in earlier publications of Vietzke et al. $[15,16]$ the hydrocarbon $\left(\mathrm{CH}_{3}\right.$ and $\left.\mathrm{CH}_{4}\right)$ production yields of a-C:H films were published. Zecho et al. have shown that $\mathrm{CH}_{3}$ and $\mathrm{CH}_{4}$ contribute about $35 \%$ to the total erosion yield. In fact, the yields in Refs. $[15,16]$ are about a factor of 3 lower. The chemical erosion yields given in Ref. [17] show the same general trend and comparable position of the maximum, but the absolute values are a factor of 5 to 8 higher than our data (maximum yield at $720 \mathrm{~K}=0.12$ ). In this respect it has to be noted that the chemical erosion yield sensitively depends on the actual microstructure of the investigated carbon material $[15,17,28,35]$ which can lead to a variation of the order of a factor of 10 [15]. On the other hand, the data of Vietzke et al. [15-17] could be inaccurate by a factor of 5 to 10 due to a large uncertainty of the hydrogen atom flux measurement. This is hard to asses since the determination of the hydrogen atom flux was never discussed by Vietzke et al.

Also shown in Fig. 2 are results of Horn et al. [27]. What is actually displayed in the figure are the model results (dashed line) of Horn et al. [27] which were fitted to the experimental data. These data, measured for ultrathin, ion-beam-deposited $\mathrm{a}-\mathrm{C}: \mathrm{H}$ films in an ultra high vacuum experiment are in reasonable agreement with our data, but give a systematically lower yield than our measurements. The uncertainty of the flux measurement and accordingly of the determined yields published by Horn et al. was mentioned to be of the order of a factor of 3 [21]. The maximum yield of Horn et al. is 0.009. The increase with increasing temperature is in excellent agreement with our data, however, there are significant deviations at high temperature. It has to be noted that measurements at high temperatures are complicated by the fact that the films start to undergo temperature induced changes, so that the detailed behaviour at high temperature can depend to a substantial extent on the temperature history of the sample and the exact experimental procedure.

Figure 3 a shows chemical sputtering yields for combined exposure to $\mathrm{Ar}^{+}$and $\mathrm{H}^{0}$. In contrast to the measurements for $\mathrm{H}^{0}$ only, which are also shown, we find measurable yields in the temperature range below $340 \mathrm{~K}$. In the range from 110 to $340 \mathrm{~K}$, the yields are independent of temperature. The yields increase with increasing ion energy from about 1 (per impinging $\mathrm{Ar}^{+}$ion) at $50 \mathrm{eV}$ to about 4 at $800 \mathrm{eV}$. These data are in excellent agreement with the previously measured energy dependence of chemical sputtering [7-10]. It has been shown before that the yield for the chemical sputtering due to combined irradiation with argon ions and $\mathrm{H}^{0}$ depends on the neutral-to-ion flux ratio $R$ [8]. For the measurements shown in Fig. 3 the flux ratios are between 340 and 360. The constancy of the yield for temperatures below $340 \mathrm{~K}$ compares nicely with the results of E. de Juan Pardo et al. [36]. They measured the methane production yield for bombardment of pyrolytic graphite with $30 \mathrm{eV}$ deuterium ions and found that the value stays constant in the temperature range from about 120 to $350 \mathrm{~K}$. 

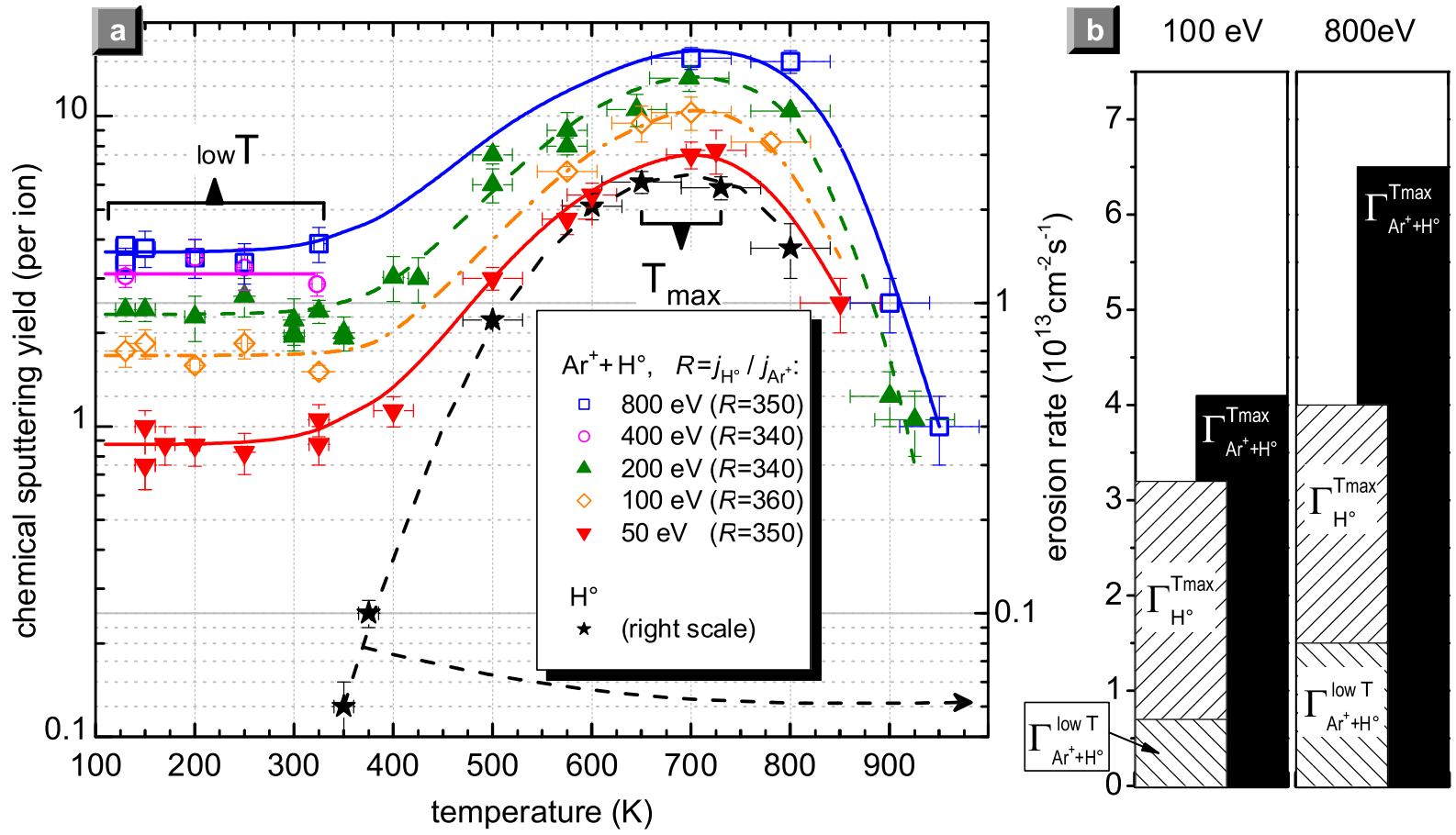

FIG. 3: a) Chemical sputtering of a-C:H films due to combined exposure to argon ions and thermal, atomic hydrogen as a function of temperature for different argon ion energies. The neutral-to-ion flux ratios $R$ are between 340 and 360 . For comparison, the data for $\mathrm{H}^{0}$ only (chemical erosion) are also shown. Lines are only a guide to the eye. b) Comparison of the sum of the chemical sputtering rate at $340 \mathrm{~K}$ $\left(\Gamma_{A r^{+}+H^{0}}^{\text {low } T}\right)$ and the chemical erosion rate at $700 \mathrm{~K}$ due to atomic hydrogen alone $\left(\Gamma_{H^{0}}^{T_{\max }}\right)$ (hatched bars) with the measured value $\left(\Gamma_{A r^{+}+H^{0}}^{T_{\max }}\right)$ for 100 and $800 \mathrm{eV}$ ion energy (solid black bars). In contrast to a) these data are presented on a linear scale.

All experiments were performed with a constant hydrogen flux of about $1.2 \times 10^{15} \mathrm{~cm}^{-2} \mathrm{~s}^{-1}$. Therefore, we can directly compare the measured rates for the different experiments. Because we use different normalizations of the yields for the two different cases $\left(\mathrm{H}^{0}\right.$-only or $\mathrm{H}^{0}$ plus ions), it is more convenient to make the following comparison for the rates. For temperatures above $340 \mathrm{~K}$ the rates for $\mathrm{Ar}^{+}$plus $\mathrm{H}^{0}$ shows the same temperature dependence as for the $\mathrm{H}^{0}$-only case, but they are in the complete temperature range systematically higher than for $\mathrm{H}^{0}$ only. The difference to the $\mathrm{H}^{0}$-only case increases monotonically with increasing ion energy. It seems that the curves for the different ion energies do not intersect, but are higher than for the $\mathrm{H}^{0}$-only case by a constant factor. As a first explanation for this ion-induced enhancement we could assume that the behavior at high temperatures can be explained by two contributions. The first being the energy-dependent but temperature-independent chemical sputtering observed at low temperature (i.e. below $340 \mathrm{~K}$ ). The second contribution is the temperature-dependent yield due to $\mathrm{H}^{0}$ only. This attempt of an explanation is illustrated in Fig. 3b. Shown is-on a linear scale-the erosion rate at 100 and $800 \mathrm{eV}$. The hatched areas represent the measured erosion rates at $340 \mathrm{~K}$ at the corresponding energy and the rate at $T_{\max }$ for $\mathrm{H}^{0}$ only, respectively. Fig. $3 b$ shows that the measured rates for $\mathrm{Ar}^{+}$plus $\mathrm{H}^{0}$ (black bars) are in both cases higher than the sum of these two processes, so that this simple assumption fails to explain the data. Obviously, at higher temperatures the synergistic effect is stronger than at low temperature. We interpret this as an indication that the damage produced by the ion bombardment causes an enhanced reactivity of the surface towards reaction with atomic hydrogen without influencing the activation energy. This means that the temperature dependence shows the identical analytical behaviour, but with an enhanced efficiency compared to the $\mathrm{H}^{0}$-only case. As a result, the curves for different ion energies are shifted with respect to the $\mathrm{H}^{0}$ only case by an energy-dependent factor. The experimental observations and the given interpretation are in excellent agreement with the Roth model [29, 30]. This model gives an analytical description of chemical sputtering for bombardment of graphite with hydrogen ions. Although this model can not be applied for our case it comprises the main physical and chemical interactions which are important for the interpretation of our experiments, namely damage production by energetic species and chemical reactions of atomic hydrogen with this damage. Roth and García-Rosales model the enhancement of the efficiency of the chemical erosion step by an energy-dependent factor.

\section{SUMMARY}

The temperature dependence of chemical erosion and chemical sputtering of a-C:H films due to exposure to hydrogen atoms $\left(\mathrm{H}^{0}\right)$ alone and combined exposure to argon 
ions and $\mathrm{H}^{0}$ was measured. The chemical erosion yield for $\mathrm{H}^{0}$ alone is below $3 \times 10^{-4}$ for temperatures below about $340 \mathrm{~K}$. It increases strongly with increasing temperature, goes through a maximum around 650 to $700 \mathrm{~K}$ and decreases again for higher temperatures. This behaviour is in general agreement with published data on the temperature dependence for this system. The quantitative agreement with the results of Horn et al. [27] is fair. Published results of Vietzke et al. $[17,18]$ are roughly a factor of 5 to 8 higher. This might be due to a different structure of the deposited film which was shown to have a strong influence on the measured erosion yields.

Combined exposure to $\mathrm{Ar}^{+}$and $\mathrm{H}^{0}$ results in measurable chemical sputtering yields in the temperature range below $340 \mathrm{~K}$. In this range the yield does not depend on temperature, but it increases with energy from about 1 (per impinging $\mathrm{Ar}^{+}$ion) to about 4 if the ion energy is increased from 50 to
$800 \mathrm{eV}$. The energy dependence at $\mathrm{T}<340 \mathrm{~K}$ is in excellent agreement with recently published data [7-10].

For temperatures above $340 \mathrm{~K}$ the yield shows the same temperature dependence as for the $\mathrm{H}^{0}$-only case, but the yields are higher than for $\mathrm{H}^{0}$-only. The erosion yield at these high temperatures can not be explained by the sum of the energydependent yield at room temperature and the temperaturedependent yield for the $\mathrm{H}^{0}$-only case. The measured yields are in fact systematically higher than this sum. The difference increases monotonically with increasing ion energy. This can be interpreted as an energy-dependent enhancement of the chemical erosion yield as has been postulated by Roth and GarcíaRosales $[29,30]$ to model the chemical sputtering of graphite at elevated temperatures.
[1] G. Federici, P. Andrew, P. Barabaschi, J. Brooks, R. Doerner, A. Geier, A. Herrmann, G. Janeschitz, K. Krieger, A. Kukushkin, A. Loarte, R. Neu, G. Saibene, M. Shimada, G. Strohmayer, M. Sugihara, Key ITER plasma edge and plasma-material interaction issues, J. Nucl. Mater. 313-316 (2003) 11-22.

[2] A. Loarte, B. Lipschultz, A. S. Kukushkin, G. F. Matthews, P. C. Stangeby, N. Asakura, G. F. Counsell, G. Federici, A. Kallenbach, K. Krieger, A. Mahdavi, V. Philipps, D. Reiter, J. Roth, J. Strachan, D. Whyte, R. Doerner, T. Eich, W. Fundamenski, A. Herrmann, M. Fenstermacher, P. Ghendrih, M. Groth, A. Kirschner, S. Konoshima, B. LaBombard, P. Lang, A. W. Leonard, P. Monier-Garbet, R. Neu, H. Pacher, B. Pegourie, R. A. Pitts, S. Takamura, J. Terry, E. Tsitrone, the ITPA Scrape-off Layer and Divertor Physics Topical Group, Progress in the ITER physics basis, Chapter 4: Power and particle control, Nucl. Fusion 47 (2007) S203-S263, Special Issue.

[3] G. Counsell, P. Coad, C. Grisolia, C. Hopf, W. Jacob, A. Kirschner, A. Kreter, K. Krieger, J. Likonen, V. Philipps, J. Roth, M. Rubel, E. Salancon, A. Semerok, F. Tabares, A. Widdowson, Tritium retention in next step devices and the requirements for mitigation and removal techniques, Plas. Phys. Control. Fusion 48 (2006) B189-B199.

[4] R. A. Causey, J. N. Brooks, G. Federici, Tritium inventory and recovery in next-step fusion devices, Fusion Eng. Des. 61-62 (2002) 525-536.

[5] W. Jacob, J. Roth, Chemical sputtering, in: R. Behrisch, W. Eckstein (Eds.), Sputtering by Particle Bombardment IV, Vol. 110 of Topics in Applied Physics, Springer Verlag, Berlin, 2007, Ch. Chemical Sputtering, pp. 329-400.

[6] E. Vietzke, A. A. Haasz, Chemical erosion, in: W. O. Hofer, J. Roth (Eds.), Physical Processes of the Interaction of Fusion Plasmas with Solids, Academic, New York, 1996, pp. 135-176.

[7] C. Hopf, A. von Keudell, W. Jacob, Chemical sputtering of hydrocarbon films by low-energy $\mathrm{Ar}^{+}$ion and $\mathrm{H}$ atom impact, Nucl. Fusion 42 (2002) L27.

[8] C. Hopf, A. von Keudell, W. Jacob, Chemical sputtering of hydrocarbon films, J. Appl. Phys. 94 (2003) 2373.

[9] C. Hopf, W. Jacob, A. von Keudell, Ion-induced surface activation, chemical sputtering, and hydrogen release during plasmaassisted hydrocarbon film growth, J. Appl. Phys. 97 (2005)
094904-1.

[10] W. Jacob, C. Hopf, M. Schlüter, Chemical sputtering of carbon materials due to combined bombardment by ions and atomic hydrogen, Phys. Scripta T124 (2006) 32-36.

[11] E. Vietzke, K. Flaskamp, V. Philipps, Hydrocarbon formation in the reaction of atomic hydrogen with pyrolytic graphite and the synergistic effect of argon ion bombardment, J. Nucl. Mater. 111-112 (1982) 763-768.

[12] E. Vietzke, K. Flaskamp, V. Philipps, Differences in the $\mathrm{CH}_{3}$ and $\mathrm{CH}_{4}$ formation from graphite under bombardment with hydrogen ions and hydrogen atoms / argon ions, J. Nucl. Mater. 128-129 (1984) 545-550.

[13] J. W. Davis, A. A. Haasz, P. C. Stangeby, Hydrocarbon formation due to combined $\mathrm{H}^{+}$ion and $\mathrm{H}^{0}$ atom impact on pyrolytic graphite, J. Nucl. Mater. 155-157 (1988) 234-240.

[14] J. W. Davis, A. A. Haasz, P. C. Stangeby, Flux and energy dependence of methane production from graphite due to $\mathrm{H}^{+}$impact, J. Nucl. Mater. 145-147 (1987) 417-420.

[15] E. Vietzke, V. Philipps, K. Flaskamp, C. Wild, The reaction of atomic hydrogen with plasma deposited a-C:H films, in: P. Koidl, P. Oelhafen (Eds.), Amorphous hydrogenated carbon films, E-MRS Symposia Proc., Vol. XVII, Les Éditions de Physique, Les Ulis, 1987, p. 351.

[16] E. Vietzke, K. Flaskamp, V. Philipps, G. Esser, P. Wienhold, J. Winter, Chemical erosion of amorphous hydrogenated carbon films by atomic and energetic hydrogen, J. Nucl. Mater. 145147 (1987) 443-447.

[17] E. Vietzke, V. Philipps, Hydrocarbon formation on carbon surfaces facing a hydrogen plasma, Fusion Technol. 15 (1989) $108-117$.

[18] E. Vietzke, V. Philipps, K. Flaskamp, P. Koidl, C. Wild, The reaction of atomic hydrogen with $\mathrm{a}-\mathrm{C}: \mathrm{H}$ and diamond films, Surf. Coat. Technol. 47 (1991) 156-161.

[19] T. Zecho, B. D. Brandner, J. Biener, J. Küppers, Hydrogeninduced chemical erosion of a-C:H thin films: Product distribution and temperature dependence, J. Phys. Chem. B 105 (2001) 6194.

[20] T. Zecho, B. D. Brandner, J. Biener, J. Küppers, Hydrogeninduced chemical erosion of a-C:H thin films: Structure and reactivity, J. Phys. Chem. B 106 (2002) 610.

[21] J. Küppers, The hydrogen surface chemistry of carbon as a 
plasma facing material, Surf. Sci. Rep. 22 (1995) 249.

[22] A. Schenk, J. Biener, B. Winter, C. Lutterloh, U. Schubert, J. Küppers, Mechanism of chemical erosion of sputterdeposited C:H films, Appl. Phys. Lett. 61 (1992) 2414.

[23] A. Schenk, B. Winter, J. Biener, C. Lutterloh, U. Schubert, J. Küppers, Growth and thermal decomposition of ultrathin ionbeam deposited C:H films, J. Appl. Phys. 77 (1995) 2462.

[24] J. Biener, U. Schubert, A. Schenk, B. Winter, C. Lutterloh, J. Küppers, A surface reaction with atoms: Hydrogenation of sp- and $\mathrm{sp}^{2}$-hybridized carbon by thermal H(D) atoms, J. Chem. Phys. 99 (1993) 3125-3128.

[25] J. Biener, A. Schenk, B. Winter, U. Schubert, C. Lutterloh, J. Küppers, Spectroscopic investigation of electronic and vibronic properties of ion-beam-deposited and thermally treated ultrathin C:H films, Phys. Rev. B 49 (1994) 17307.

[26] J. Biener, A. Schenk, B. Winter, C. Lutterloh, U. Schubert, J. Küppers, Hydrogenation of amorphous C:H surfaces by thermal H(D) atoms, Surf. Sci. 307-309 (1994) 228.

[27] A. Horn, A. Schenk, J. Biener, B. Winter, C. Lutterloh, M. Wittmann, J. Küppers, $\mathrm{H}$ atom impact induced chemical erosion reaction at $\mathrm{C}: \mathrm{H}$ film surfaces, Chem. Phys. Lett. 231 (1994) 193

[28] T. Schwarz-Selinger, A. von Keudell, W. Jacob, Novel method for absolute quantification of the flux and angular distribution of a radical beam source for atomic hydrogen, J. Vac. Sci. Technol. A 18 (2000) 995 .
[29] J. Roth, C. García-Rosales, Analytic description of the chemical erosion of graphite by hydrogen ions, Nucl. Fusion 36 (1996) 1647-1659, see also corrigendum: J. Roth and C. GarcíaRosales, Nucl. Fusion 37, 897 (1997).

[30] J. Roth, Chemical erosion of carbon based materials in fusion devices, J. Nucl. Mater. 266-269 (1999) 51.

[31] W. Jacob, C. Hopf, A. von Keudell, M. Meier, T. SchwarzSelinger, Particle-beam experiment to study heterogeneous surface reactions relevant to plasma-assisted thin film growth and etching, Rev. Sci. Instrum. 74 (2003) 5123-5136.

[32] Colutron Research Corporation, 2321 Yarmouth Ave., Boulder, CO 80301 USA, http://www.colutron/products/.

[33] W. Jacob, Surface reactions during growth and erosion of hydrocarbon films, Thin Solid Films 326 (1998) 1.

[34] T. Schwarz-Selinger, A. von Keudell, W. Jacob, Plasma chemical vapor deposition of hydrocarbon films: The influence of hydrocarbon source gas on the film properties, J. Appl. Phys. 86 (1999) 3988.

[35] A. von Keudell, W. Jacob, Growth and erosion of hydrocarbon films, investigated by in situ ellipsometry, J. Appl. Phys. 79 (1996) 1092.

[36] E. de Juan Pardo, M. Balden, B. Cieciwa, C. García-Rosales, J. Roth, Erosion processes of carbon materials under hydrogen bombardment and their mitigation by doping, Phys. Scripta T111 (2005) 62-67. 